\title{
Effect of adrenaline, noradrenaline, atropine, and nicotine on some types of human tremor
}

\author{
JOHN MARSHALL AND HAROLD SCHNIEDEN ${ }^{1}$
}

\author{
From the Institute of Neurology, Queen Square, London
}

Barcroft, Peterson, and Schwab (1952) and more recently Constas (1962) have shown that an intravenous infusion of adrenaline aggravates the tremor of patients with Parkinsonism. This observation raises two interesting questions. First, what are the effects on tremor of other drugs which act upon the autonomic nervous system? An answer to this question might throw some further light upon the pharmacological mechanisms responsible for the tremor. Secondly, do other forms of tremor show a different response to drugs than does the tremor of Parkinsonism? An answer to this question might provide a more objective classification of the various forms of tremor than is at present provided by clinical observation alone. In the present study the effect of four substances upon five clinical types of tremor has been observed and the results are reported here.

\section{METHOD}

Tremor was recorded by means of a valve sensitive to acceleration which the patient held in the hand in which the tremor was most apparent to the naked eye. In the case of patients with head tremor the valve was strapped firmly on to the forehead. Movement of the valve upset the balance of a bridge circuit and the electrical output after amplification was recorded by a pen writing on moving paper. From the tracings at least six random samples each of five seconds' duration were obtained using random number tables. The maximum amplitude in each sample was measured and the mean maximum amplitude was then calculated both for the control tracings and for those obtained after administration of the drug. The mean percentage change in maximum amplitude produced by the drug as compared to the control could then be calculated and the statistical significance of this change assessed. Further details of the technique and of the apparatus used are given in the papers of Marshall and Walsh (1956) and Marsh, Schnieden, and Marshall (1963). Twenty-two patients were studied in all: seven had essential tremor, eight Parkinsonian tremor, three cerebellar tremor, one a tremor due to a high brainstem lesion, and three a tremor associated with anxiety. The patients were of both sexes and their ages ranged from 25 to 74 years. Noticeable tremor had been present for at least one year.

${ }^{1}$ Present address: Department of Pharmacology, University of Manchester,
RESULTS

EFFECT OF ADRENALINE Adrenaline $\left(18 \mu \mathrm{g} . / \mathrm{min} . \frac{\mathrm{O}}{\bar{\omega}}\right.$ in $0.9 \%$ sodium chloride solution) was infused intra- $\frac{\widehat{\phi}}{\sigma}$ venously at a constant rate $(0.45 \mathrm{ml} . / \mathrm{min}$.) from $\mathrm{a} \cong$ constant infusion motor-driven syringe, the patients $\infty$ previously having had their tremor recorded during $\vec{\circ}$ a control infusion of isotonic saline. It can be seenfrom Table I that adrenaline $18 \mu \mathrm{g}$./min. produced a $\bar{\omega}$ significant increase in the tremor in 17 out of $18 \frac{2}{5}$ patients tested. It increased the tremor of patients with Parkinsonian, essential, anxiety, and cerebellari type tremors. The only exception was one patient (B) who developed a tremor following a high brainstemin lesion in the region of the red nucleus. An illustre $\vec{A}-\vec{A}$ tion of the degree of increase in a patient with Parlig-을 sonism is given in Figure 1.

EFFECT OF NORADRENALINE Noradrenaline was a a ministered in a similar concentration $(18 \mu \mathrm{g} . / \mathrm{min} \overrightarrow{\mathrm{\sigma}} \cdot \overrightarrow{\mathrm{\theta}}$ As can be seen from Table I, however, no consistent pattern, as was found with adrenaline, was obtained. In some patients significantly increased response was observed (four out of 18 patients), in others a significantly decreased tremor response (six out of $18 \mathrm{D}$ patients), whilst in the remainder the degree of

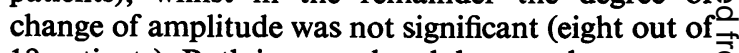
18 patients). Both increased and decreased responses응 were found in patients with Parkinsonism and in patients with essential tremor, while all three patients with cerebellar tremor showed a decreased response

EFFECT OF ATROPINE This was given as a single intravenous injection $(0.6 \mathrm{mg}$.) during a saline in fusion. It can be seen from Table I that again a vari-o̊ able response was found. In nine patients an in -2 crease in tremor was noted approximately 20 minuteso after injection, six of these reaching levels of significance, whereas in nine others a decreased response음 occurred (six being significant). Two-thirds of the responses fell between -38 and +60 of the controlos values. At the time of recording the patients noticed N that their mouths were dry suggesting atropine hadN reached receptors in the salivary glands. 


\section{TABLE I}

EFFECT OF ADRENALINE AND NORADRENALINE INFUSION AND OF A SINGLE INTRAVENOUS INJECTION OF ATROPINE OR OF NICOTINE (2 MG.) ON MEAN MAXIMUM AMPLITUDE OF TREMOR IN PATIENTS WITH TREMOR ${ }^{1}$

Mean Percentage Change in Maximum Amplitude of Tremor

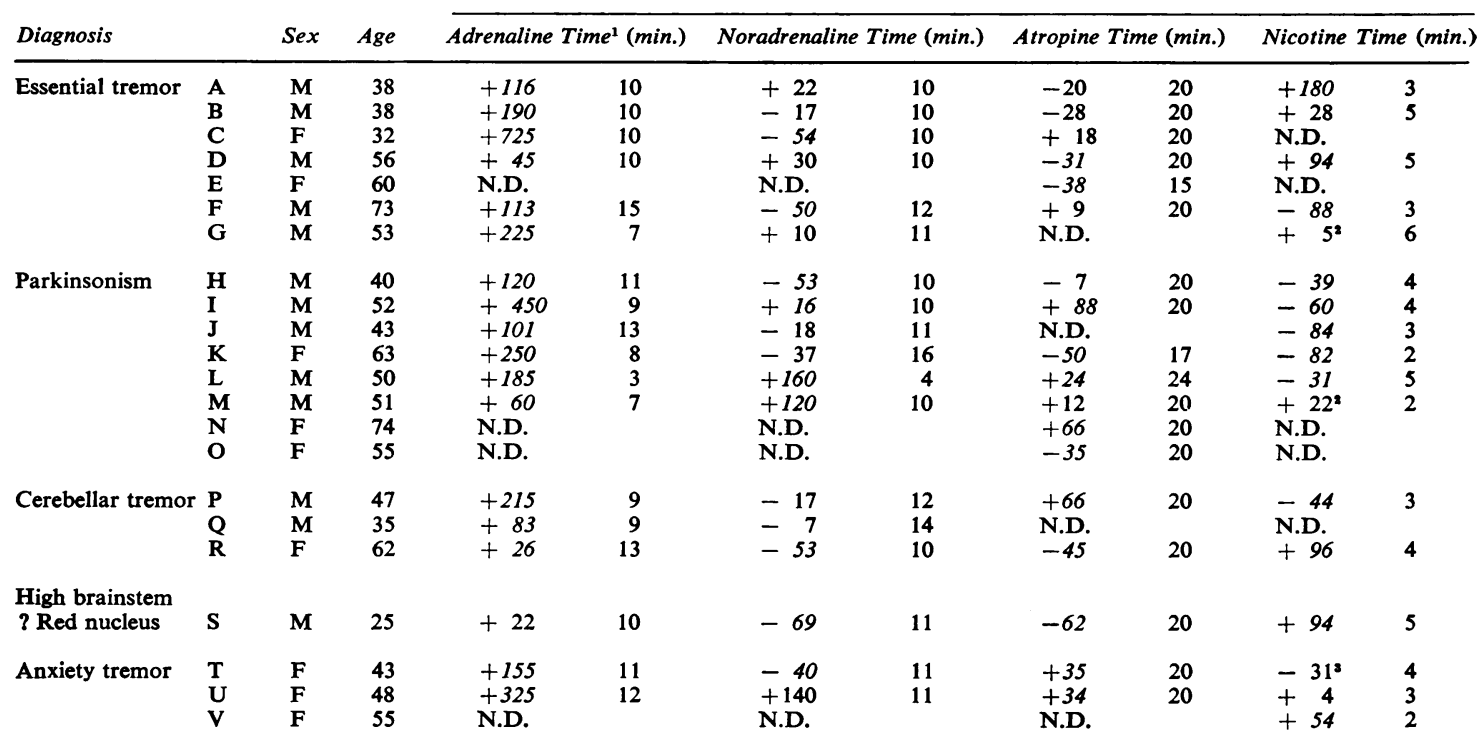

${ }^{1}$ Times in minutes indicates how long after the start of the infusion or the giving of injection the recording was made. The figures in italics indicate a percentage change which was significant at the $5 \%$ level. Patients $B$ and $C$ had marked head tremor.

${ }^{2}$ Given only $1 \mathrm{mg}$. nicotine.

${ }^{3}$ Given only $1.5 \mathrm{mg}$. nicotine.

\section{$10 \mathrm{~mm}$.}

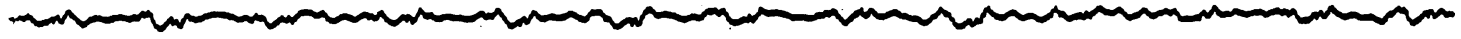

FIG. 1a sec.

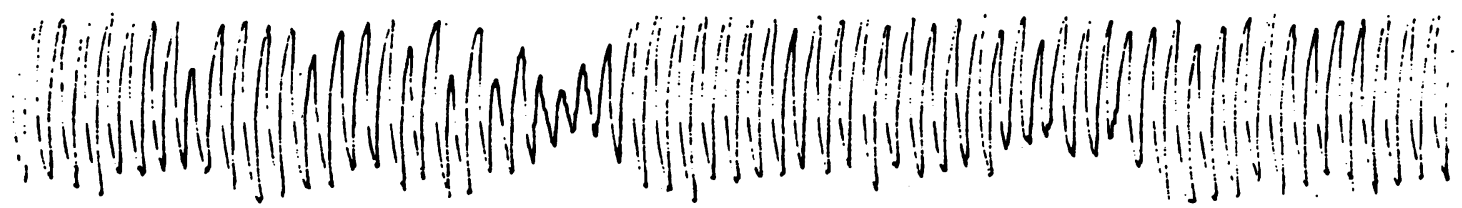

FIG. $1 b$

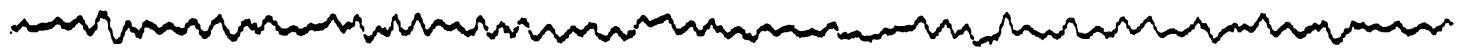

FIG. 1c

FIG. 1. Effect of adrenaline, $18 \mu \mathrm{g} . / \mathrm{min}$., for 10 minutes in a patient with essential tremor (head tremor recorded).

(a) Before adrenaline.

(b) 10 minutes after adrenaline infusion was started.

(c) 15 minutes after infusion of adrenaline was stopped. 
10 m̄m.

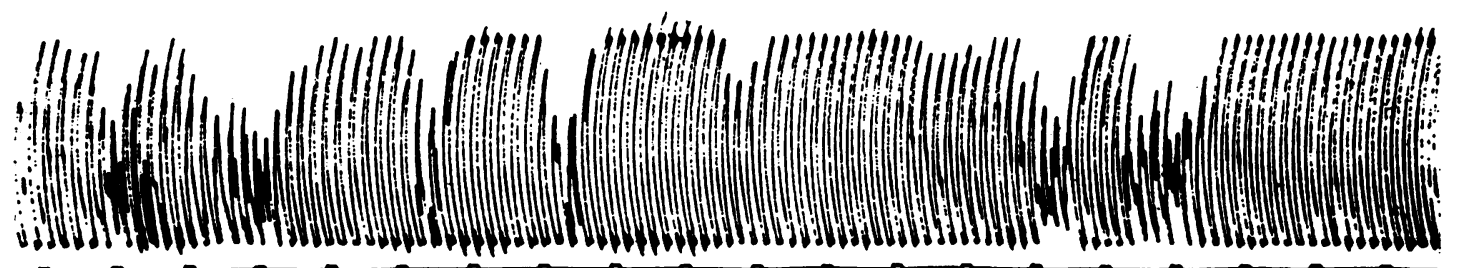

Sec.

FIG. $2 \mathrm{a}$

$10 \overline{m m}$.

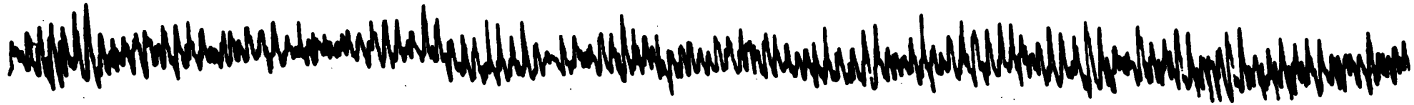

sec.

FIG. $2 b$

$10 \mathrm{~mm}$.

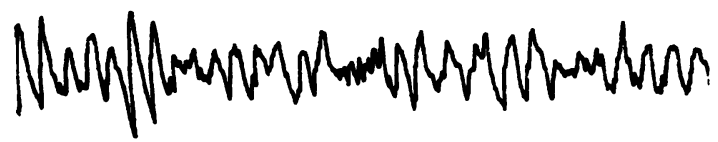

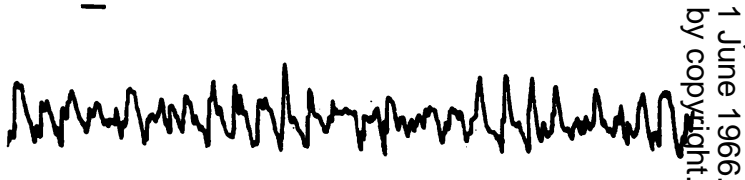

Sec.

Sec.

FIG. $3 a$

FIG. 3c

$10 \mathrm{~mm}$.

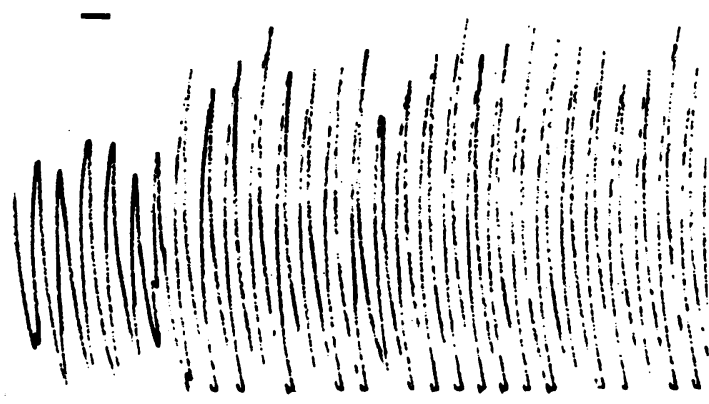

Sec.
FIG. 2. (a) Tremor recorded before administration of nicotine hydrogen tartrate.

(b) Tremor recorded three minutes after intravenous injection of $6 \mathrm{mg}$. nicotine hydrogen tartrate to a patient with Parkinsonism.

FIG. 3. Effect of mental arithmetic on Parkinsonian 을 tremor.

(a) Before.

(b) 8 seconds after commencement of mental arithmetic.

(c) 8 seconds after completion of mental arithmetic.

FIG. $3 b$ 
EFFECT OF NICOTINE This drug was given as nicotine hydrogen tartrate 3 to $6 \mathrm{mg}$. (equivalent to 1 to $2 \mathrm{mg}$. base) intravenously as a single injection during a saline infusion and was injected at the rate of $1 \mathrm{mg}$. base/minute. Five patients with Parkinsonian tremor received $6 \mathrm{mg}$. of nicotine hydrogen tartrate ( $2 \mathrm{mg}$. base) and in all the tremor was reduced (Fig. 2). One patient received only $3 \mathrm{mg}$. of nicotine hydrogen tartrate and a slight increase of tremor occurred.

Four patients with essential tremor showed an increase of tremor after nicotine, but in a fifth patient the tremor was reduced.

During the injection of the $6 \mathrm{mg}$. dose of nicotine the patients often had symptoms. A tingling in the arm being injected, spreading to the other arm and legs, was often reported, followed by a sensation of numbness which lasted only for a few seconds. The patients also felt sick and perspired profusely. Some patients developed a noticeable pallor. These effects were less marked in patients who had a history of taking cigarettes. However, the depression of tremor did not appear to be related to the severity of the symptoms stated above.

EFFECTS OF STRESS Finally, the influence that stress might have upon the results was studied in the patients with Parkinsonism. A number of patients with Parkinsonism were asked to subtract 7 from 100 and 7 from their subsequent answers whilst their tremor was being recorded. In seven out of eight patients the tremor increased during the test (Fig. 3). In one patient no significant change in tremor was noted. As some stress may be experienced during an infusion, the effect of this was observed. Figure 4 shows a recording of a patient's tremor immediately before, and some time after, the infusion of isotonic saline. It can be seen that there is a marked diminution in tremor.

\section{DISCUSSION}

The results show that relatively low concentrations of adrenaline $(18 \mu \mathrm{g}$./min.) can produce a marked increase in tremor, not only in patients with Parkinsonism but also in patients with tremor due to other diseases. This suggests that either there is a common pathway involved on which adrenaline acts or that adrenaline tremor is superimposed on the existing tremor either summating with it or potentiating it. It has further been demonstrated that apprehension and stress can markedly increase tremor, confirming the results of Barcraft et al. (1952), who noted that mental arithmetic increased Parkinsonian tremor. It is probable that such stress phenomena involve the release of adrenaline since the mental arithmetic test is known to affect sympathetic vasomotor tone (Blair, Glover, Greenfield, and Roddie,

\section{$10 \overline{m m}$.}

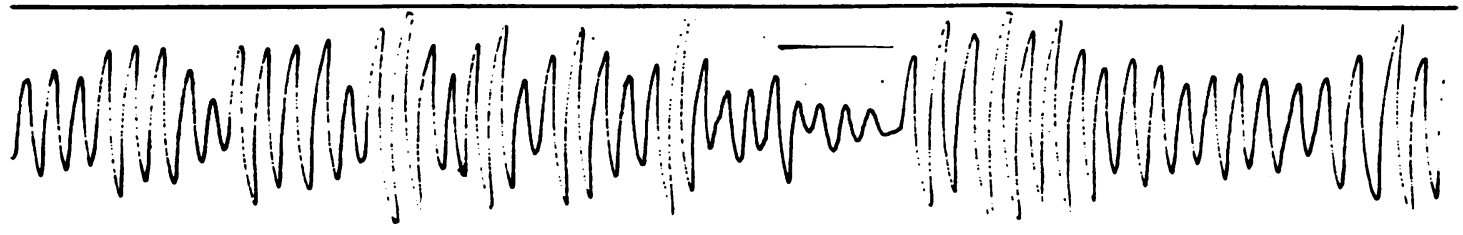

FIG. $4 \mathrm{a}$

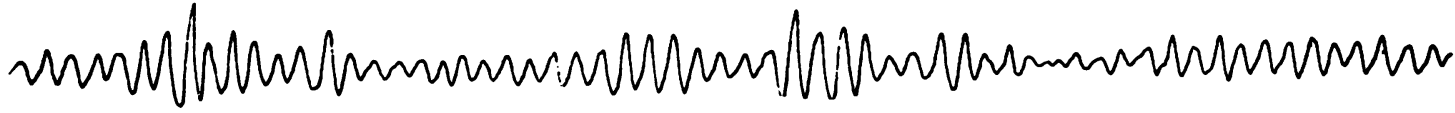

sec.

FIG. $4 b$

FIG. 4. Effect of anxiety on essential tremor.

(a) Before intravenous infusion of saline.

(b) 50 minutes later. 
1959; Barcroft, Brod, Hejl, Hirsjärvi, and Kitchin, 1960) and it can be blocked by bretylium tosylate (French and Matthews, 1961).

What is of therapeutic importance is the magnitude of the response. In 13 of the patients examined the tremor response was at least doubled and a threefold increase was quite common. It is well known that many tremor patients lead a secluded life because they find their tremor increases when they are in such stressful situations as occasioned by meeting strangers. If, as is probable, this increase is due to adrenaline release, a possible therapeutic attack can be made on this problem. There are now quite a range of compounds which can modify adrenaline release or block its effects, and a trial of some of these in man in these conditions should be of considerable interest.

Atropine is not a very effective drug in controlling tremor in man (Doshay, 1953). In experimental tremor in monkeys Jenker and Ward (1953) have also found atropine relatively ineffective. The present finding of an increase in the amplitude of tremor in many patients about 20 minutes after atropine is, however, slightly surprising. It is known that atropine has initially a stimulating effect on the central nervous system before producing depression, and it may be that with the single dose this factor was important.

Nicotine $(2 \mathrm{mg}$.) had a depressant effect on the tremor of Parkinsonian patients but had no consistent effect on the other forms of tremor. Both acetylcholine and nicotine can stimulate parts of the nervous system in low doses and produce a block in higher doses. Jenkner and Ward (1953) have suggested that in Parkinsonism there is increased responsiveness of cells to acetylcholine in the tremorproducing area so that stimulation and block would occur with lower concentrations of the drug than normally. If the same argument can be applied to nicotine this may be an explanation why depression of tremor regularly occurred in the Parkinsonian patients whilst stimulation occurred frequently in patients with other forms of tremor. It is of interest that a slight increase in tremor occurred in the one patient with Parkinsonism given a lower dose of nicotine $(1 \mathrm{mg}$.). This would support the above hypothesis.

The results of this work indicate that the increase in Parkinsonian tremor caused by adrenaline is largely, though not entirely, drug specific. None of the other three drugs tested had so consistent an effect upon the amplitude of the tremor and in those instances in which there was an increase it was not of the same magnitude as that produced by adrenaline. In the other forms of tremor which were tested a similar pattern was found; adrenaline increased the amplitude of the tremor, and the other drugs pro- $\frac{0}{Z}$ duced a variable response, though whenever there $\underset{\mathbb{Q}}{Z}$ was an increase it was rarely so great as that pro- $\frac{C}{5}$ duced by adrenaline. The only suggestion of a con- of sistent response, apart from that of adrenaline, was the effect of nicotine upon Parkinsonian tremor, $D$ there being a depression of the amplitude of the tremor. Unfortunately the difference between the $\stackrel{5}{5}$. effect of nicotine upon Parkinsonian and other types $\stackrel{0}{\rightleftharpoons}$ of tremor was not so clear cut as to form at this?. stage a means of classifying the tremors pharma- $\vec{F}$ cologically but further work along these lines would clearly be profitable.

\section{SUMMARY}

The effect of adrenaline, noradrenaline, atropine, and nicotine has been investigated in 22 patients with $\vec{\circ}$ tremor. Of these, eight patients had Parkinsonism and seven patients had essential tremor. Adrenaline $\vec{\omega}$ was given by intravenous infusion to 18 patients; tremor increased in 17 of these patients. All six patients with essential tremor who received adrenal- if ine produced an increase in tremor. Stress produce ${ }_{\omega}^{0}$ by mental arithmetic increased tremor in seven out iv of eight Parkinsonian patients and apprehensio $\vec{A}$ could be shown to increase the tremor in a patient 0 with essential tremor. The implications of these findings are discussed.

Both noradrenaline intravenously and atroping intravenously had a variable effect on tremor bot $\vec{\oplus}$ nicotine $(2 \mathrm{mg}$.) caused a marked diminution $\overrightarrow{\mathrm{f}} \overline{\mathrm{\theta}}$ tremor within a few minutes in patients with Parkiñ-? sonism. In patients with tremor of different causation, this dose of nicotine could produce an increase in tremor.

\section{REFERENCES}

Barcroft, H., Brod, J., Hejl, Z., Hirsjärvi, E. A., and Kitchin, A. H. $\overrightarrow{\bar{O}}$ (1960). The mechanism of the vasodilatation in the forearm muscle during stress (mental arithmetic). Clin. Sci., 19, 577-586. , Peterson, E., and Schwab, R. S. (1952). Action of adrenaline and noradrenaline on the tremor in Parkinson's disease. Neurology (Minneap.), 2, 154-160.

Blair, D. A., Glover, W. E., Greenfield, A. D. M., and Roddie, I. C. (1959). Excitation of cholinergic vasodilator nerves to human skeletal muscles during emotional stress. J. Physiol. (Lond.), 148, 633-647.

Constas, C. (1962). The effects of adrenaline, noradrenaline, and? isoprenaline on Parkinsonian tremor. J. Neurol. Neurosurg. '? Psychiat., 25, 116-121.

Doshay, L. J. (ed.) (1953). Parkinsonism and its treatment. Amer. Practit., 4, suppl. to Nov. issue, pp. 1-22.

French, E. B., and Matthews, M. B. (1961). Effects of brachial arterial infusion of bretylium tosylate on hand blood flow. Clin. Sci., D 21, 151-155.

Jenkner, F. L., and Ward, A. Jr. (1953). Bulbar reticular formation and tremor. Arch. Neurol. Psychiat. (Chic.), 70, 489-502. N

Marsh, D. O., Schnieden, H., and Marshall, J. (1963). A controlled clinical trial of alpha methyl dopa in Parkinsonian tremor. $N$ J. Neurol. Neurosurg. Psychiat., 26, 505-510.

Marshall, J., and Walsh, E. G. (1956). Physiological tremor. Ibid., $\mathrm{\omega}$ 19, 260-267. 